\title{
ENERGY RATIO OF THE SEISMIC WAVES REFLECTED AND REFRACTED AT A ROCK-WATER BOUNDARY*

\author{
By Kazim ERGIN
}

\section{INTRODUCTION}

THE SUBJECT of energy ratios of seismic waves reflected and refracted at a discontinuity has been studied by various authors; a list of references is given at the end of this paper. They deal mostly with the theory and computations concerning the cases where a wave is incident at a boundary between two solid media. Reflection at the surface of the earth has been studied by Zoeppritz, Geiger, and Gutenberg, ${ }^{1}$ Geiger and Gutenberg, ${ }^{2}$ Gutenberg, ${ }^{3}$ and Jeffreys. ${ }^{4}$ The case of the mantle-core boundary has been computed by Dana. ${ }^{5}$ The present paper deals with the case of the ocean floor. We are particularly interested in zero points and extreme points of energy ratios of waves resulting from the incidence of a wave at either side of the discontinuity.

Since this work was begun a few years ago, much progress has been accomplished in the study of microseisms and their use as a hurricane-detecting device. In this connection we hope that the results obtained in this paper may provide material for further studies concerning the passage of a wave, set up in the water by a storm, to the solid crustal layers.

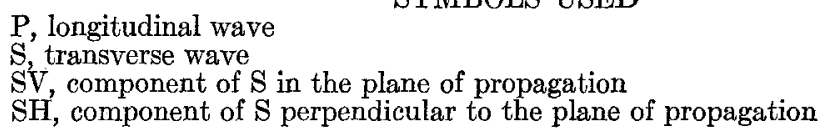

\begin{tabular}{llll}
\multicolumn{2}{c}{ Incident } & \multicolumn{2}{c}{ Reflected } \\
$\mathbf{P}$ & $\mathrm{S}$ & $\mathrm{P}$ & $\mathrm{S}$ \\
$A$ & $B$ & $C$ & $D$ \\
& & $c$ & $d$ \\
$\alpha$ & $\beta$ & $\alpha$ & $\beta$ \\
& & $V_{1 p}$ & $V_{1 s}$ \\
& & & $\rho_{1}$
\end{tabular}

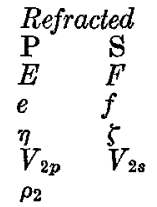

amplitudes square root of energy ratio angle of incidence velocity

$\sigma$, Poisson's ratio

$$
\begin{aligned}
& m=V_{1 p} / V_{1 s}=f(\sigma) \\
& n=V_{2 p} / V_{1 p} \\
& r=\rho_{2} / \rho_{1}
\end{aligned}
$$

\section{SYMBOLS USED}

density

Snell's law:

\section{Equations Used for Computation}

$$
\sin \alpha: \sin \beta: \sin \eta: \sin \zeta=V_{1 p}: V_{1 s}: V_{2 p}: V_{2 s}
$$

* Condensed from a Ph.D. dissertation at the California Institute of Technology. Manuscript received for publication July 5,1950 .

1 L. Zoeppritz, L. Geiger, and B. Gutenberg, "Über Erdbebenwellen. V," Nachr. Gesell. d. Wiss. Göttingen, math.-phys. Kl., 1912, pp. 121-206.

2 L. Geiger and B. Gutenberg, "Über Erdbebenwellen. VI," Nachr. Gesell. d. Wiss. Göttingen, math.-phys. Kl., 1912, pp. 623-675.

${ }^{3}$ B. Gutenberg, "Energy Ratio of Reflected and Refracted Waves," Bull. Seism. Soc. Am., 34: 85-102 (1944).

"H. Jeffreys, "The Reflection and Refraction of Elastic Waves," Mon. Not. Roy. Astron. Soc., Geophys. Suppl., 1:321-334 (1926).

S. W. Dana, "The Partition of Energy among Seismic Waves Reflected and Refracted at the Earth's Core," Bul. Seism. Soc. Am., 34:189-198 (1944). 
Blut's energy equations:

$P$ wave incident in the solid against the water:

$$
\frac{C^{2}}{A^{2}}+\frac{D^{2} \sin 2 \beta}{A^{2} \sin 2 \alpha}+\frac{E^{2} \rho_{2} \sin 2 \eta}{A^{2} \rho_{1} \sin 2 \alpha}=1
$$

or

$$
c^{2}+d^{2}+e^{2}=1
$$

$P$ wave incident in the water against the solid:

or

$$
\frac{C^{2}}{A^{2}}+\frac{E^{2} p_{2} \sin 2 \eta}{A^{2} p_{1} \sin 2 \alpha}+\frac{F^{2} \rho_{2} \sin 2 \zeta}{A^{2} p_{1} \sin 2 \alpha}=1
$$

$$
c^{2}+e^{2}+f^{2}=1
$$

SV wave incident in the solid against the water:

$$
\frac{D^{2}}{B^{2}}+\frac{C^{2} \sin 2 \alpha}{B^{2} \sin 2 \beta}+\frac{E^{2} \rho_{2} \sin 2 \eta}{B^{2} \rho_{1} \sin 2 \beta}=1
$$

or

$$
d^{2}+c^{2}+e^{2}=1
$$

Relation between $\sigma$ and $m$

$$
\sigma=\frac{1}{2}\left(1-\frac{1}{m^{2}-1}\right)
$$

The amplitude ratios $\frac{C}{A}, \frac{D}{A}, \frac{E}{A}$ and $\frac{F}{A}$ are computed from the following Zoeppritz
equations: $P$ wave incident in the solid against the water:

$$
\begin{aligned}
A \cos \alpha-C \cos \alpha+D \sin \beta-E \cos \eta & =0 \\
-A \cos 2 \beta-C \cos 2 \beta+D / m_{1} \sin 2 \beta+E n r & =0 \\
-A \sin 2 \alpha+C \sin 2 \alpha+D m_{1} \cos 2 \beta & =0
\end{aligned}
$$

Solving these three equations and making use of equation (2), and also making use of the identity

$$
m_{1} \cos 2 \beta \cos \alpha-\sin 2 \alpha \sin \beta=m_{1} \cos \alpha
$$

we get for the square root of the energy ratios $c, d$, and $e$ :

$$
\begin{aligned}
& c=\frac{\cos \eta\left(m_{1} \cos ^{2} 2 \beta-1 / m_{1} \sin 2 \alpha \sin 2 \beta\right)-m_{1} n r \cos \alpha}{\cos \eta\left(m_{1} \cos ^{2} 2 \beta+1 / m_{1} \sin 2 \alpha \sin 2 \beta\right)+m_{1} n r \cos \alpha} \\
& d=\frac{2}{\cos \eta\left(m_{1} \cos ^{2} 2 \beta+1 / m_{1} \sin 2 \alpha \sin 2 \beta\right)+m_{1} n r \cos \alpha}
\end{aligned}
$$




$$
e=\frac{2 m_{1} \sqrt{n r \cos \alpha \cos \eta} \cos 2 \beta}{\cos \eta\left(m_{1} \cos ^{2} 2 \beta+1 / m_{1} \sin 2 \alpha \sin 2 \beta\right)+m_{1} n r \cos \alpha}
$$

$P$ wave incident in the water against the solid:

$$
\begin{aligned}
A \cos \alpha-C \cos \alpha-E \cos \eta-F \sin \zeta & =0 \\
-A-C \quad+E n r \cos 2 \zeta+F \frac{m}{m_{2}} \sin 2 \zeta & =0 \\
+E \sin 2 \eta-F m_{2} \cos 2 \zeta & =0
\end{aligned}
$$

Solving these three equations and making use of equation (3), we get for the square root of the energy ratios $c, e$, and $f$ :

$$
\begin{aligned}
& \left.c=\frac{\cos \eta-n r \cos \alpha\left[1-2 \sin \zeta \sin 2 \zeta\left(\cos \zeta-1 / m_{2} \cos \eta\right)\right]}{\cos \eta+n r \cos \alpha\left[1-2 \sin \zeta \sin 2 \zeta\left(\cos \zeta-1 / m_{2} \cos \eta\right)\right.}\right] \\
& e=\frac{2 \sqrt{n r \cos \alpha \cos \eta} \cos 2 \zeta}{\cos \eta+n r \cos \alpha\left[1-2 \sin \zeta \sin 2 \zeta\left(\cos \zeta-1 / m_{2} \cos \eta\right)\right]} \\
& f=\frac{2 n / m_{2} \sqrt{r \sin 2 \alpha \sin 2 \zeta} \cos \eta}{\cos \eta+n r \cos \alpha\left[1-2 \sin \zeta \sin 2 \zeta\left(\cos \zeta-1 / m_{2} \cos \eta\right)\right]}
\end{aligned}
$$

SV wave incident in the solid against the water. (Note that in this case angle of incidence is $\beta$ ):

$$
\begin{aligned}
-B \sin \beta-C \cos \alpha+D \sin \beta-E \cos \eta & =0 \\
B \sin 2 \beta-C m_{1} \cos 2 \beta+D \sin 2 \beta+E m_{1} n r & =0 \\
-B \cos 2 \beta+C 1 / m_{1} \sin 2 \alpha+D \cos 2 \beta & =0
\end{aligned}
$$

Solving these three equations and making use of equation (4), and again making use of the identity $m_{1} \cos 2 \beta \cos \alpha-\sin 2 \alpha \sin \beta=m_{1} \cos \alpha$, we get for the square root of the energy ratios $c, d$ and $f$ :

$$
\begin{aligned}
& d=\frac{\cos \eta\left(m_{1} \cos ^{2} 2 \beta-1 / m_{1} \sin 2 \alpha \sin 2 \beta\right)+m_{1} n r \cos \alpha}{\cos \eta\left(m_{1} \cos ^{2} 2 \beta+1 / m_{1} \sin 2 \alpha \sin 2 \beta\right)+m_{1} n r \cos \alpha} \\
& c=\frac{2 \sqrt{\sin 2 \alpha \sin 2 \beta} \cos 2 \beta \cos \eta}{\cos \eta\left(m_{1} \cos ^{2} 2 \beta+1 / m_{1} \sin 2 \alpha \sin 2 \beta\right)+m_{1} n r \cos \alpha} \\
& e=\frac{2 \sqrt{r \sin 2 \beta \sin 2 \eta} \cos \alpha}{\cos \eta\left(m_{1} \cos ^{2} 2 \beta+1 / m_{1} \sin 2 \alpha \sin 2 \beta\right)+m_{1} n r \cos \alpha}
\end{aligned}
$$


SH wave incident in the solid against the water. For this particular case Zoeppritz equations reduce to

$$
B=D
$$

so that all of the energy is reflected as SH wave for all angles of incidence.

$$
\text { Extreme Points of } \sqrt{E_{\text {ref } \mathrm{p}} / E_{\text {ine } \mathrm{p}}} \text { and } \sqrt{E_{\text {ref s }} / E_{\text {inc s }}}
$$

Differentiating (7) with respect to $\beta$ and putting $\frac{\partial c}{\partial \beta}=0$ we get

$$
\begin{aligned}
& 2\left(1-m_{1}^{2}\right) \sin ^{4} \beta+\left(3 m_{1}^{2}-1\right) \sin ^{2} \beta-2 \\
& \quad+\frac{n r}{1-2 \sin ^{2} \beta}\left(1-\bar{m}_{1}^{2} \sin ^{2} \beta\right)^{3 / 2}\left(1-\sin ^{2} \beta\right)=0
\end{aligned}
$$

The value of $\beta$ that satisfies this equation is the angle of incidence of the reflected $S$ wave at which the reflected $P$ wave has its extreme value. The corresponding value of a can be computed from Snell's law

$$
\sin \alpha: \sin \beta=V_{1 p} / V_{1 s}
$$

When a $\mathrm{P}$ wave is incident at the surface of the earth, then $n=0$, and the following equation gives the extreme points of the energy ratio of the $\mathrm{P}$ wave reflected at the surface of the earth,

$$
2\left(1-m_{1}^{2}\right) \sin ^{4} \beta+\left(3 m_{1}^{2}-1\right) \sin ^{2} \beta-2=0
$$

Last term of the equation ( $7 \mathrm{a}$ ) is very small compared to the rest of the terms. The same statement is also true for the equation (7). This fact can be used to explain the similarity in the behavior of the reflected wave that is of the same type as the incident wave, in both cases, i.e., the rock-water boundary and the surface of the earth.

In the case of an SV wave incident in the rock against the water, we get a similar expression for the extreme points of the reflected SV wave, the only difference being that the sign of the last term is negative.

$$
\begin{aligned}
& 2\left(1-m_{1}^{2}\right) \sin ^{4} \beta+\left(3 m_{1}^{2}-1\right) \sin ^{2} \beta-2 \\
& \quad-\frac{n r}{1-2 \sin ^{2} \beta}\left(1-m_{1}^{2} \sin ^{2} \beta\right)^{\prime / 2}\left(1-\sin ^{2} \beta\right)=0
\end{aligned}
$$

When an SV wave is incident at the surface of the earth we again get the equation (7b). This result should be expected, because for the surface of the earth the expression giving $\sqrt{E_{\text {ref } \mathrm{p}} / E_{\text {ine } \mathrm{p}}}$ is the same as the expression giving $\sqrt{E_{\mathrm{ref} \mathrm{s}} / E_{\text {inc s }} \text {. (See }}$ Gutenberg, "Theorie der Erdbebenwellen.") 


\section{Computed Values}

In general, computation falls into three groups:

1) The general behavior of the energy ratio for each case involves calculation of the square root of the energy ratio for a sufficient number of the angles of incidence. This was done with a slide rule to the third decimal place, using one of the equations $(7),(8),(9),(11),(12),(13),(15),(16)$, and (17), as the case might be.

2) The angle of incidence (if any) at which an energy ratio becomes zero was determined, first, by determining this angle from the graphs showing the general behavior of the energy ratio, approximately, and then by computing more values with a calculating machine to the fourth decimal place in the neighborhood of the approximate value. The final value of the zero point was thus determined graphically.

3) The angle of incidence (if any) at which an energy ratio has an extreme value was also determined graphically.

The computation is carried out for possible values of three parameters, namely, $m, n$, and $r$. Results are tabulated and plotted against the angle of incidence and are given in the following pages. For the general case, according to Gutenberg, "the results of calculations are in good agreement with the observations. However, for a wave which travels almost tangent to the discontinuity and in the medium with higher velocity, the calculated energy may be much too small."6 The same situation should be true for the special cases considered here.

\section{P WAVE INCIDENT IN THE SOLID AGAINST THE WATER}

Using equations (7), (8), and (9), energy ratios are computed for the following values of parameters: $m_{1}=1.6,1.7,1.8 ; n=0.2,0.3,0.4 ; r=0.3,0.4,0.5$.

For different values of parameters, values of $c$ as a function of $a$ are given in table 1, values of $a_{0}$ ( $\alpha$ for which $c=0$ ) in table 2, and values of $a_{\text {ext }}$ ( $a$ for which $c$ has an extreme value) in table 3 . Figure 1 shows the general behavior of $c$. In order that the effect of each parameter should be shown, two of them were kept constant and the energy ratios were computed for three different values of the third parameter $\left(m_{1}\right.$ is varied for two sets of values of $n$ and $r$ ). From these computations it is found that the effect of changing $m_{1}$ is greater than the effect of changing either $n$ or $r$. In figure $2, a_{01}, a_{02}$, and $\alpha_{\text {ext }}$ are plotted against $m_{1}$ for different values of $n$ and $r$. Here we note that for all values of $n$ and $r$, $a$ approaches $90^{\circ}$ as $m_{1}$ approaches $\sqrt{2}(\sigma=0)$. From these curves it is evident that theoretically the $a_{0}$ curve intersects the $a_{\text {ext }}$ curve which means that there are some combinations of values of parameters for which the extreme value of $c$ is zero. The following two examples are given to illustrate the possibility of such an incidence for actual values of densities and elastic constants.

${ }_{6}^{6}$ As cited in note 3 above. He adds references to G. Joos and J. Teltow, "Zur Deutung der Knallwellenausbreitung und der Trennschicht zweier Medien," Phys. Zeitschr., 40: 289-293 (1930), and H. Ott, "Reflexion und Brechung von Kugelwellen," Ann. d. Physik, 38: 443-466 (1942). 
TABLE 1

Incident P Wave in the Solid against the Water: Square Root of the Energy Ratio of The Reflected P Wave

(For the purpose of showing the change of sign at zero points, the energy ratio is tabulated with the sign of the amplitude ratio.)

\begin{tabular}{|c|c|c|c|c|c|c|c|c|c|c|}
\hline \multirow{2}{*}{\multicolumn{2}{|c|}{$\frac{m \ldots \ldots \ldots \ldots \ldots}{r \ldots \ldots \ldots \ldots \ldots}$}} & \multicolumn{3}{|c|}{1.6} & \multicolumn{3}{|c|}{1.7} & \multicolumn{3}{|c|}{1.8} \\
\hline & & 0.3 & 0.4 & 0.5 & 0.3 & 0.4 & 0.5 & 0.3 & 0.4 & 0.5 \\
\hline \multirow[t]{4}{*}{$n$} & a. (deg.) & 87 & 0852 & -0818 & 37 & 3 & 818 & -0887 & $85 ?$ & \\
\hline & 0 & $\begin{array}{r}-0.888 \\
-\quad 831\end{array}$ & $\begin{array}{r}-0.802 \\
-\quad 707\end{array}$ & $\left\{\begin{array}{r}-0.818 \\
-\quad 764\end{array}\right.$ & 848 & 502 & $\begin{array}{l}818 \\
779\end{array}$ & $\begin{array}{r}-0.881 \\
850\end{array}$ & 852 & 818 \\
\hline & 20 & -.672 & -.641 & -.611 & -.708 & $-\quad 676$ & -.645 & $\begin{array}{r}-736 \\
-\quad .736\end{array}$ & -.705 & $-\quad 673$ \\
\hline & 30 & -.439 & -.411 & -.385 & -.513 & -.484 & -.457 & -.571 & -.542 & -.514 \\
\hline \multirow[t]{6}{*}{0.2} & 40 & -.163 & -.141 & -.119 & -.283 & -.259 & -.235 & $-\quad 378$ & -.352 & -.327 \\
\hline & 50 & +.106 & +.123 & +.140 & -.057 & -.038 & -.018 & -.195 & -.172 & -.150 \\
\hline & 60 & +.327 & +.340 & +.353 & +.115 & +.137 & +.148 & -.062 & -.043 & -.024 \\
\hline & 70 & +.462 & +.473 & +.483 & +.197 & +.212 & +.225 & -.013 & +.001 & +.019 \\
\hline & 80 & +.406 & +.415 & +.426 & +.060 & +.074 & +.088 & -.193 & -.178 & -.164 \\
\hline & 90 & -1.000 & -1.000 & -1.000 & -1.000 & -1.000 & -1.000 & -1.000 & -1.000 & -1.000 \\
\hline \multirow{10}{*}{0.4} & 0 & -0.786 & -0.724 & -0.667 & -0.786 & -0.724 & -0.667 & -0.786 & -0.724 & -0.667 \\
\hline & 10 & -.732 & -.672 & -.616 & -.741 & -.680 & -.624 & -.749 & -.690 & -.634 \\
\hline & 20 & -.580 & -.524 & -.473 & -.614 & -.558 & -.505 & -.636 & -.584 & -.531 \\
\hline & 30 & -.357 & -.308 & -.264 & -.428 & -.377 & -.330 & -.475 & -.434 & -.380 \\
\hline & 40 & -.096 & -.056 & -.019 & -.209 & -.164 & -.123 & -.292 & -.250 & -.208 \\
\hline & 50 & +.159 & +.191 & +.220 & +.005 & +.014 & +.075 & -.120 & -.085 & -.047 \\
\hline & 60 & +.369 & +.393 & +.415 & +.170 & +.201 & +.229 & -.001 & +.034 & +.068 \\
\hline & 70 & +.496 & +.515 & +.532 & $1+.244$ & +.270 & +.295 & +.030 & +.063 & +.103 \\
\hline & 80 & +.441 & +.461 & +.479 & +.105 & +.133 & +.158 & +.149 & +.117 & +.082 \\
\hline & 90 & -1.000 & -1.000 & -1.000 & -1.000 & -1.000 & -1.000 & -1.000 & -1.000 & -1.000 \\
\hline
\end{tabular}

TABLE 2

Inctdent P Wave in the Solid against the Water: Angles of Incidence at Which the Energy Ratio of the Reflected P Wave is Zero

\begin{tabular}{|c|c|c|c|c|c|c|c|}
\hline \multicolumn{2}{|c|}{$r$} & \multicolumn{2}{|c|}{0.3} & \multicolumn{2}{|c|}{0.4} & \multicolumn{2}{|c|}{0.5} \\
\hline$n$ & $m$ & $a_{01}$ & $\alpha_{02}$ & $a_{01}$ & $a_{02}$ & $a_{01}$ & $a_{02}$ \\
\hline 0.2 & $\begin{array}{l}1.60 \\
1.65 \\
1.70 \\
1.75 \\
1.785\end{array}$ & $\begin{array}{cc}\text { deg. } & \text { min. } \\
45 & 58 \\
49 & 11 \\
52 & 48 \\
58 & 03 \\
64.5\end{array}$ & $\begin{array}{ll}\text { deg. } & \text { min. } \\
86 & 32 \\
84 & 27 \\
81 & 32 \\
77 & 19 \\
72.0\end{array}$ & $\begin{array}{cc}\text { deg. } & \text { min. } \\
45 & 10 \\
48 & 20 \\
52 & 00 \\
56 & 40\end{array}$ & $\begin{array}{cc}\text { deg. } & \text { min. } \\
86 & 38 \\
84 & 30 \\
81 & 50 \\
77 & 52\end{array}$ & $\begin{array}{cc}\text { deg. } & \text { min. } \\
44 & 30 \\
47 & 30 \\
51 & 04 \\
55 & 28\end{array}$ & $\begin{array}{rr}\text { deg. } & \text { min. } \\
86 & 45 \\
84 & 40 \\
82 & 08 \\
78 & 23\end{array}$ \\
\hline 0.3 & $\begin{array}{l}1.60 \\
1.65 \\
1.70 \\
1.75\end{array}$ & $\begin{array}{ll}44 & 46 \\
47 & 49 \\
51 & 25 \\
56 & 04\end{array}$ & $\begin{array}{ll}86 & 41 \\
84 & 42 \\
82 & 02 \\
78 & 21\end{array}$ & $\begin{array}{ll}43 & 45 \\
46 & 36 \\
50 & 08 \\
54 & 05\end{array}$ & $\begin{array}{ll}86 & 51 \\
84 & 55 \\
82 & 13 \\
78 & 59\end{array}$ & $\begin{array}{ll}42 & 38 \\
45 & 41 \\
48 & 33 \\
52 & 24\end{array}$ & $\begin{array}{ll}86 & 57 \\
85 & 07 \\
82 & 41 \\
79 & 35\end{array}$ \\
\hline 0.4 & $\begin{array}{l}1.60 \\
1.65 \\
1.70 \\
1.75 \\
1.80\end{array}$ & $\begin{array}{ll}43 & 34 \\
46 & 34 \\
49 & 49 \\
53 & 58 \\
59 & 41\end{array}$ & $\begin{array}{ll}86 & 40 \\
85 & 20 \\
82 & 27 \\
78 & 54 \\
74.0\end{array}$ & $\begin{array}{ll}42 & 12 \\
44 & 44 \\
47 & 50 \\
51 & 38 \\
56 & 16\end{array}$ & $\begin{array}{ll}86 & 59 \\
85 & 22 \\
83 & 02 \\
79 & 52 \\
75 & 45\end{array}$ & $\begin{array}{ll}40 & 52 \\
43 & 15 \\
46 & 13 \\
49 & 28 \\
53 & 28\end{array}$ & $\begin{array}{ll}87 & 07 \\
85 & 27 \\
83 & 16 \\
80 & 40 \\
77 & 03\end{array}$ \\
\hline
\end{tabular}




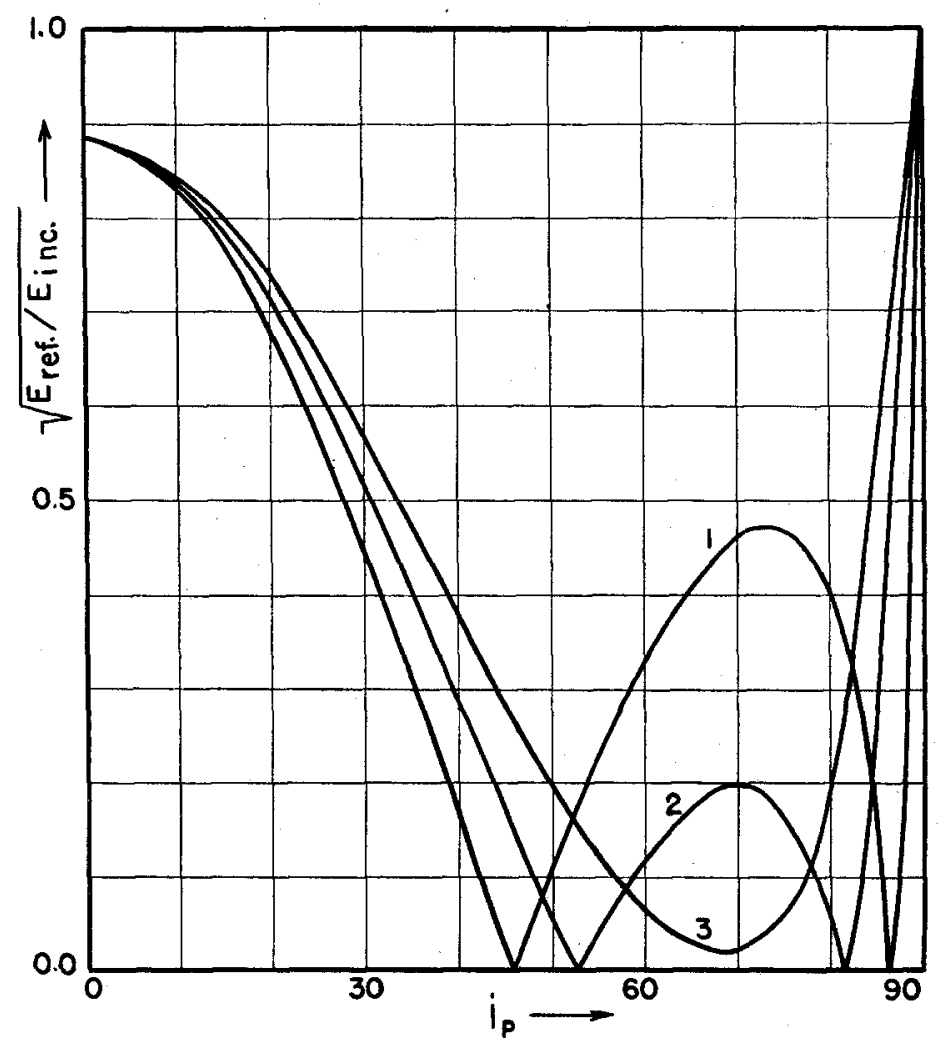

Fig. 1. $\mathrm{P}$ wave incident in the solid against the water. Square root of the energy ratio of the reflected $P$ wave.

$\begin{array}{cccc}\text { Curve } & V_{1 p} / V_{1 s} & V_{2 p} / V_{1 p} & \rho_{2} / \rho_{1} \\ 1 & 1.6 & 0.2 & 0.3 \\ 2 & 1.7 & 0.2 & 0.3 \\ 3 & 1.8 & 0.2 & 0.3\end{array}$

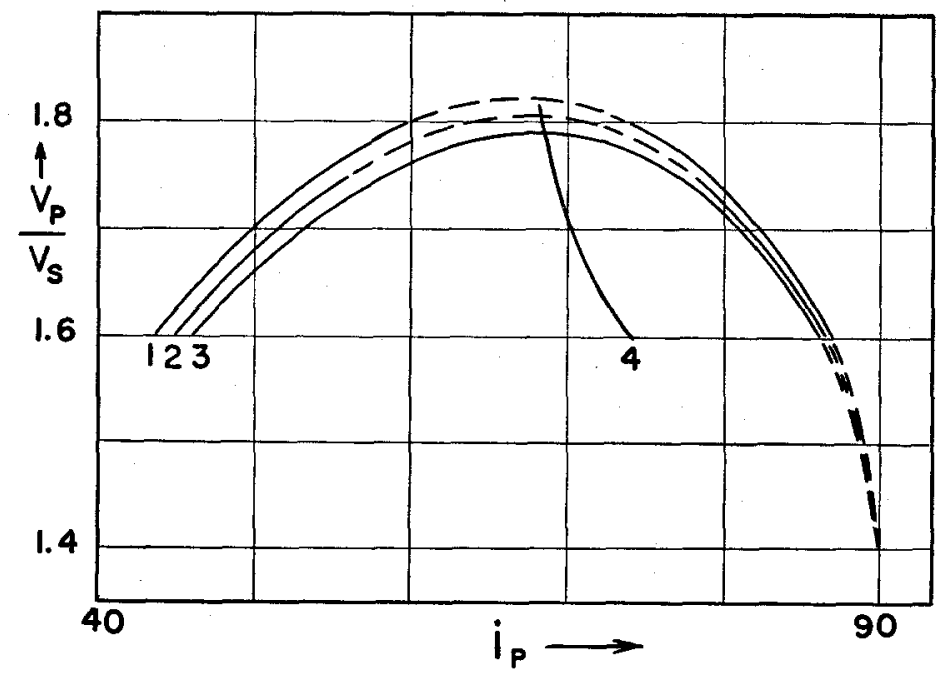

Fig. 2. $\mathrm{P}$ wave incident in the solid against the water.

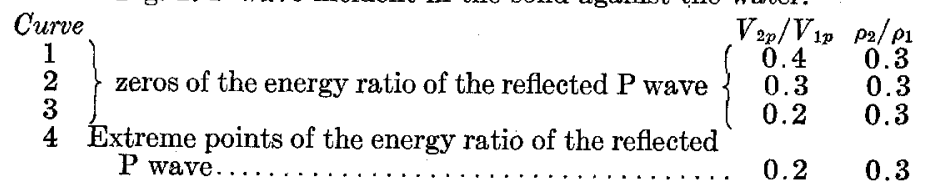


Example 1. Granite-sea water boundary:

$\begin{array}{lrlll}V_{1 \mathrm{p}}=5.55 & V_{1 \mathrm{~s}}=3.26 & V_{2 \mathrm{p}}=1.5 & \rho_{2}=1.026 & \rho_{1}=2.9 \\ \text { Hence } & \sigma=0.24 & m_{1}=1.70 & n=0.27 & r=0.354\end{array}$

These values of parameters are represented by the curves and corresponding values of $a_{01}, a_{02}$ and $\alpha_{\text {ext }}$ can easily be obtained by interpolation. It is evident that for this example $c$ has two distinct roots and one extreme value between them.

Example 2. Ultrabasic rock-sea water boundary:

$$
\begin{array}{lllll}
V_{1 \mathrm{p}}=8.0 & V_{1 \mathrm{~s}}=4.4 & V_{2 \mathrm{p}}=1.5 & \rho_{2}=1.026 & \rho_{1}=3.3 \\
\text { Hence } & \sigma=0.27 & m_{1}=1.82 & n=0.1875 & r=0.311
\end{array}
$$

From the curves it is evident that for these values of parameters $c$ has no roots, but it has an extreme value. Thus, we conclude that for a solid medium with seismic velocities and density lying between those for granite and an ultrabasic rock such as dunite, $c$ may have an extreme point which is at the same time a double root of the equation.

In table 4 , the values of $d$ and $a_{\text {ext }}$ for $d$ are given for different values of parameters. The values of $d$ are plotted in figure 3 . Changes in $r$ produce very little change in $d$. $d$ starts from zero at $a=0^{\circ}$ increases rapidly. For small values of $m_{1}$ it has two distinct maxima and a minimum in-between. As $m_{1}$ increases the extreme points become less pronounced and for $m_{1}=1.8$ they are represented by a flat section between $\alpha=60^{\circ}$ and $\alpha=80^{\circ}$. $a_{\text {ext }}$ are not affected very much as we vary $n$ and $r$.

Table 5 and figure 4 show the values of $e$ for different values of parameters. $e$ starts with a value $\frac{2 \sqrt{n r}}{1+n r}$ at $a=0^{\circ}$; as a increases, it diminishes very slowly, but in the neighborhood of $a=90^{\circ}$ very sharply and becomes zero at $a=90^{\circ}$. For smaller $m_{1}$ it shows a slight increase after $a \sim 75^{\circ}$ and around $a \sim 87$ it starts decreasing sharply to zero at $a=90^{\circ}$. As $m_{1}$ takes larger values this tendency seems to disappear. Changes in $n$ and $r$ have negligible effect on these turning points. For larger values of $n, e$ has larger values at all angles of incidence. This simply means that the less longitundinal velocity contrast we have, the more energy goes into the refracted $P$ wave.

\section{P WAVE INCIDENT IN THE WATER AGAINST THE SOLID}

Using equations (11), (12), and (13), energy ratios are computed for the following values of parameters: $m_{2}=1.6,1.7,1.8(\sigma=0.18-0.277) ; n=3.0,4.0 ; r=2.5,3.0$.

For this particular case we have total reflections, occurring twice; namely, one at $\eta=90^{\circ}$ and one at $\zeta=90^{\circ}$. We shall call corresponding angles of incidence $\alpha_{c \eta}$ and $a_{c \zeta}$ respectively in the following discussions. At these critical incidences all of the energy is reflected as $\mathrm{P}$ wave.

Values of $c, e$, and $f$ are given in tables 6,7 , and 8 , respectively; those for $a_{\text {ext }}$, in table 9 . These results are plotted in figures 5 and 6 .

$c$ starts with a value $\frac{1-r n}{1+r n}$ at $a=0^{\circ}$, staying almost constant until near $a_{c \eta}$. As $a_{c \eta}$ is approached it rapidly increases and becomes one at $a_{c \eta}$. Right after, it suddenly drops down to a value less than it has for $a<a_{c \eta}$, then it starts increasing slowly, the rate of increase diminishing gradually, and as it gets close to $a_{c \zeta}$ it starts 


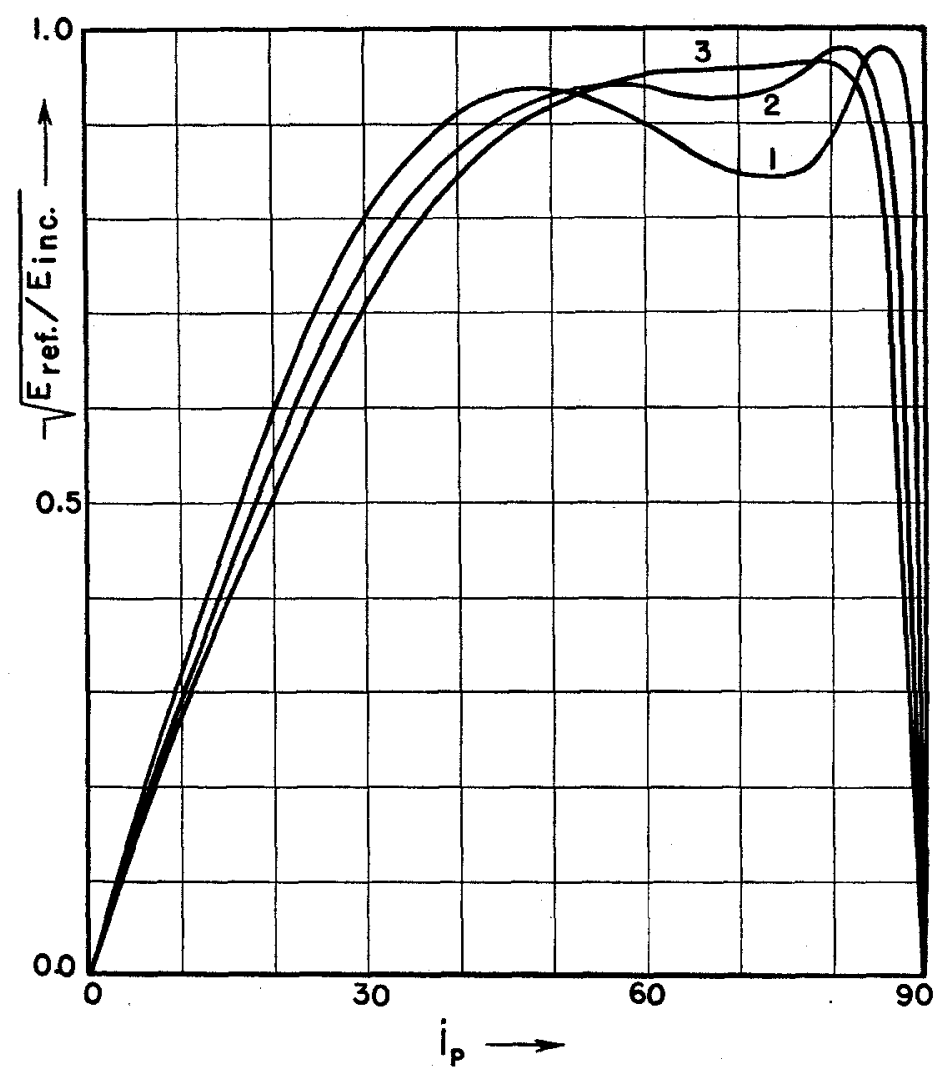

Fig. 3. $\mathrm{P}$ wave incident in the solid against the water. Square root of the

\begin{tabular}{cccc}
\multicolumn{4}{c}{ energy ratio of the reflected SV wave. } \\
Curve & $V_{1 p} / V_{1 s}$ & $V_{2 p} / V_{1 p}$ & $\rho_{2} / \rho_{1}$ \\
1 & 1.6 & 0.2 & 0.3 \\
2 & 1.7 & 0.2 & 0.3 \\
3 & 1.8 & 0.2 & 0.3
\end{tabular}

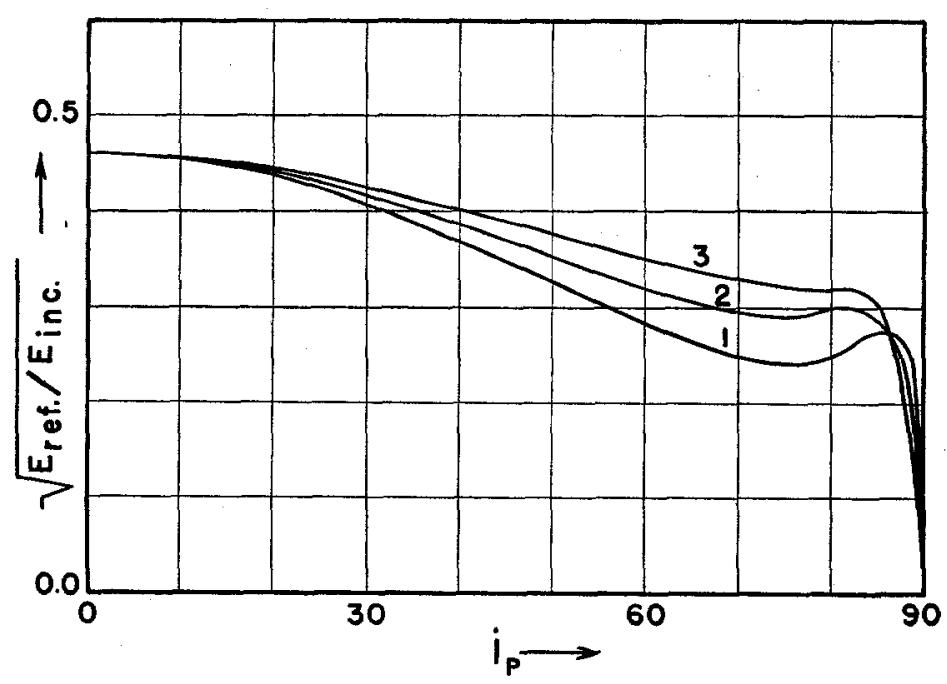

Fig. 4. $\mathrm{P}$ wave incident in the solid against the water. Square root of the

$\begin{array}{cccc}\text { energy ratio of the refracted } \mathrm{P} \text { wave. } \\ \text { Curve } & V_{1 p} / V_{1 s} & V_{2 p} / V_{1 p} & \rho_{2} / \rho_{1} \\ 1 & 1.6 & 0.2 & 0.3 \\ 2 & 1.7 & 0.2 & 0.3 \\ 3 & 1.8 & 0.2 & 0.3\end{array}$


TABLE 3

Incident P Wave in the Solid against the Water: Angles of Incidence at Which the Energy Ratio of the Reflected P Wave Has Its Extreme Value (For the purpose of showing the change of sign at zero points, the energy ratio is tabulated with the sign of the amplitude ratio.)

\begin{tabular}{|c|c|c|c|c|}
\hline 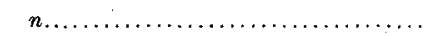 & \multicolumn{2}{|c|}{0.2} & 0.2 & 0.4 \\
\hline$\ldots \ldots \ldots$ & \multicolumn{2}{|c|}{0.3} & 0.6 & 0.3 \\
\hline$m_{1}$ & $a_{a x t}$ & $c$ & $a_{e x t}$ & $a_{\mathrm{ext}}$ \\
\hline & deg. $\min$. & & deg. min. & deg. min. \\
\hline $1.60 \ldots \ldots \ldots \ldots$ & 7400 & +0.4725 & & \\
\hline $1.65 \ldots \ldots \ldots$ & $71 \quad 41$ & +0.3280 & & \\
\hline $1.70 \ldots \ldots \ldots$ & $\begin{array}{ll}70 & 08\end{array}$ & +0.1973 & & \\
\hline $1.75 \ldots \ldots \ldots \ldots$ & $68 \quad 50$ & +0.0830 & $68 \quad 45$ & $68 \quad 36$ \\
\hline $1.79 \ldots \ldots \ldots$ & $68 \quad 25$ & +0.000 & & \\
\hline $1.80 \ldots \ldots \ldots \ldots \ldots$ & $68 \quad 15$ & -0.0185 & & \\
\hline
\end{tabular}

TABLE 4

INCIDENT P Wave in the Solid Against the Water

(a) THE SQUARE ROOT OF THE ENERGY RATIO OF THE REFLECTED S WAVE

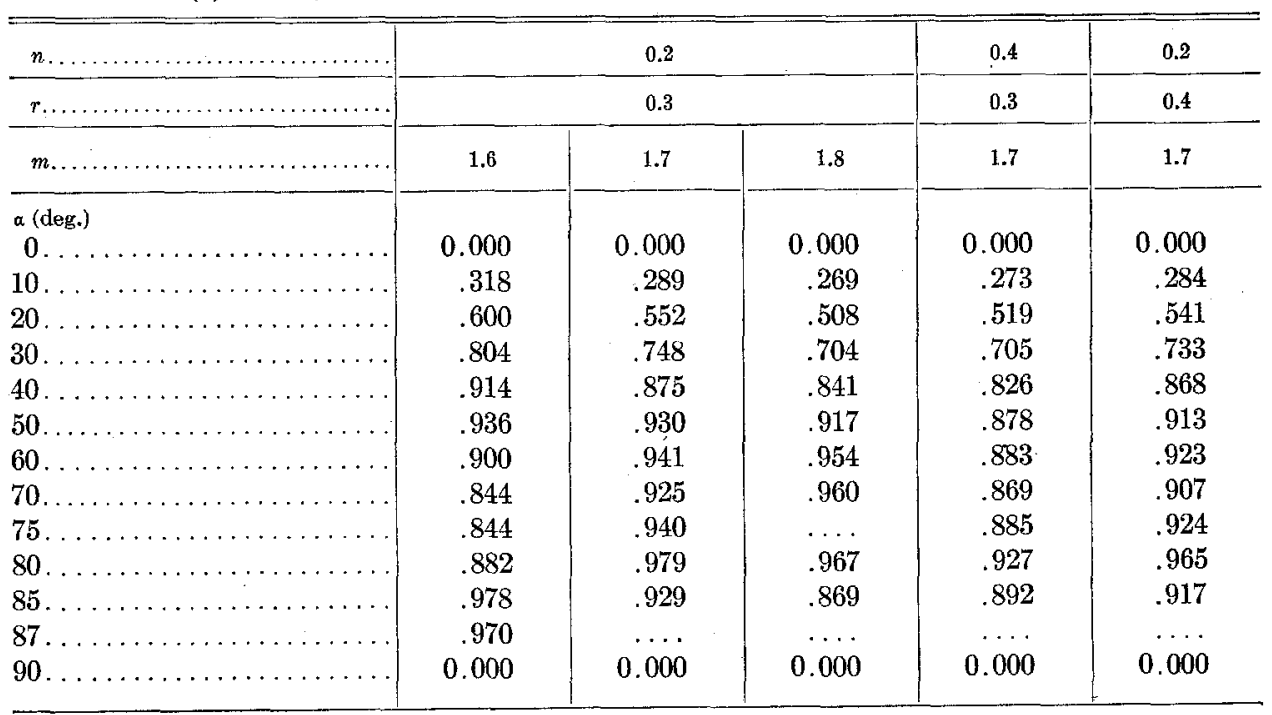


TABLE 4 (Continued)

(b) ANGLES OF INCIDENCE AT WHICH THE ENERGY RATIO OF THE REFLECTED S WAVE HAS ITS EXTREME VALUE

\begin{tabular}{|c|c|c|c|}
\hline$n \ldots \ldots \ldots, \ldots, \ldots, \ldots, \ldots, \ldots$ & \multicolumn{3}{|c|}{0.2} \\
\hline 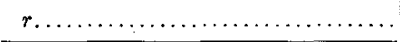 & \multicolumn{3}{|c|}{0.3} \\
\hline$m_{\mathfrak{1}}$ & $a_{\text {ext }}$ & aest & $\alpha_{\text {ext }}$ \\
\hline $1.60 \ldots \ldots \ldots \ldots$ & 48.2 & $73: 2$ & $86: 5$ \\
\hline 1.65. & 51.7 & 71.5 & 84.2 \\
\hline 1.70 . & 56.5 & 68.5 & 81.5 \\
\hline $1.725 \ldots$ & 60 & 66 & \\
\hline $1.75 \ldots \ldots \ldots$ & $\ldots$ & $\ldots$ & 76 \\
\hline
\end{tabular}

TABLE 5

Incident P WaVe in the Solid against the Water: Square Root of the Energy Ratio of the Refracted P Wave

\begin{tabular}{|c|c|c|c|c|c|}
\hline${ }_{n} \ldots \ldots \ldots \ldots \ldots \ldots \ldots \ldots \ldots \ldots \ldots \ldots$ & \multicolumn{3}{|c|}{0.2} & 0.4 & 0.2 \\
\hline$r \ldots \ldots \ldots \ldots \ldots \ldots \ldots \ldots \ldots$ & \multicolumn{3}{|c|}{0.3} & 0.3 & 0.4 \\
\hline$m_{\mathbf{1}} \ldots \ldots \ldots$ & 1.6 & 1.7 & 1.8 & 1.7 & 1.7 \\
\hline$a$ (deg.) & & & & & \\
\hline 0. & 0.462 & 0.462 & 0.462 & 0.618 & 0.453 \\
\hline $10 \ldots \ldots$ & .455 & .457 & .458 & .614 & .448 \\
\hline $20 \ldots \ldots \ldots$ & .432 & .440 & .442 & .593 & .431 \\
\hline $30 \ldots \ldots \ldots \ldots$ & .415 & .419 & .426 & .562 & .411 \\
\hline $40 \ldots \ldots \ldots$ & .370 & .387 & .402 & .517 & .380 \\
\hline $50 \ldots \ldots \ldots \ldots$ & .325 & .351 & .373 & .475 & .345 \\
\hline $60 \ldots \ldots \ldots \ldots$ & .284 & .321 & .352 & .433 & .315 \\
\hline $70 \ldots \ldots \ldots \ldots$ & .250 & .294 & .330 & .404 & .288 \\
\hline $75 \ldots \ldots \ldots \ldots$ & .242 & .292 & .322 & .400 & .287 \\
\hline 80. & .251 & .300 & .319 & .420 & .295 \\
\hline 85. & .271 & .279 & .285 & .406 & .276 \\
\hline $87 \ldots \ldots \ldots$ & .272 & .259 & .237 & $\ldots$ & $\ldots$ \\
\hline $90 \ldots \ldots \ldots \ldots$ & 0.000 & 0.000 & 0.000 & 0.000 & 0.000 \\
\hline
\end{tabular}


increasing sharply and at $a=a_{c 5}, c=1$. Values of $a$ at which the energy curve starts increasing right after $\alpha_{\mathrm{c} \eta}$ are given in table 9 .

$e$ starts with a value $\frac{2 \sqrt{n r}}{1+n r}$ at $a=0^{\circ}$, and decreases slowly until near $a_{c \eta}$, where it shows little increase before it drops to zero at $a_{c \eta}$. For small values of $m_{1}$, for instance, $m=1.3$ ( $\sigma<0$, given here just as an illustration), it has a zero between $\alpha=0^{\circ}$ and $a=a_{e \eta}$, and for large values of $m_{1}$ it is a smooth, continuously decreasing function of $a$. After $a_{c \eta}$ no refracted $P$ wave exists. $e=0$.

$f$ starts from zero at $\alpha=0$, and for a while increases almost linearly; as $a$ approaches $a_{c \eta}$, it turns down and decreases sharply to zero at $a_{c \eta}$. Right after $a_{c \eta}$ it increases suddenly and attains a value larger than it has for $a<a_{\mathrm{cn}}$. Here it turns and decreases very slowly, the rate of decrease becoming smaller, and as $a_{c 5}$ is approached it decreases sharply and becomes zero at $\alpha_{c 5}$. After $a_{c 5}$ there is no refracted $S$ wave either. Thus all the energy goes into reflected $P$ wave. Turning points occurring just before and right after $a_{c \eta}$ are given in table 9 .

It is evident that here, in this particular case, critical angles of incidences are the governing factors. All peculiarities occur just before and right after these angles.

Here we notice that most of the energy goes into the reflected $P$ wave. None of the energy ratios becomes zero except at a critical incidence. The turning points which we may call $a_{\mathrm{ext}}$ are not very much different for different values of $r$, but they depend on $m$ and $n$.

\section{SV WAVE INCIDENT IN THE SOLID AGAINST THE WATER}

Using equations (15), (16), and (17), energy ratios have been computed and their zeros and extreme points investigated for the following values of parameters: $m_{1}=1.6,1.7,1.75(\sigma=0.18-0.2576), n=0.2,0.3,0.4$ (and $\beta_{\text {ext }}$ were computed in addition to these values for $m=1.8[\sigma=0.277]) ; r=0.3$.

In this particular case there is only one total reflection at $\beta_{c a}\left(\alpha=90^{\circ}\right)$. At this critical angle of incidence $d=1, e=0, c=0$. The part of the curves for $d$ and $c$ that lies between $\beta=0$ and $\beta=\beta_{c a}$ are similar to the curves of $c$ and $d$ for the case of a $\mathrm{P}$ wave incident in the solid against the water. The curve for $e$ as a whole is similar to that of $f$ for the case of a $P$ wave incident in the water against the solid, between $a=0$ and $a=a_{c \xi}$. The only difference between these similar curves is that, in the case of incident SV wave, at normal incidence all the energy is reflected as SV wave; in other cases, at normal incidence the energy is split between $c$ and $e$.

Here again we notice that $\beta_{\text {ext }}$ are not very much different for different values of $n$ and $r$. Therefore for practical purposes $\beta_{\text {ext }}$ may be considered as a function of $m$ only.

The characteristics of the curves for SV incident in solid against water are given in tables 10-15 and figures 7-10. 
TABLE 6

Inctdent P Wave in the Water against the Solid: Square Root of the Energy Ratio of the Reflected P Wave

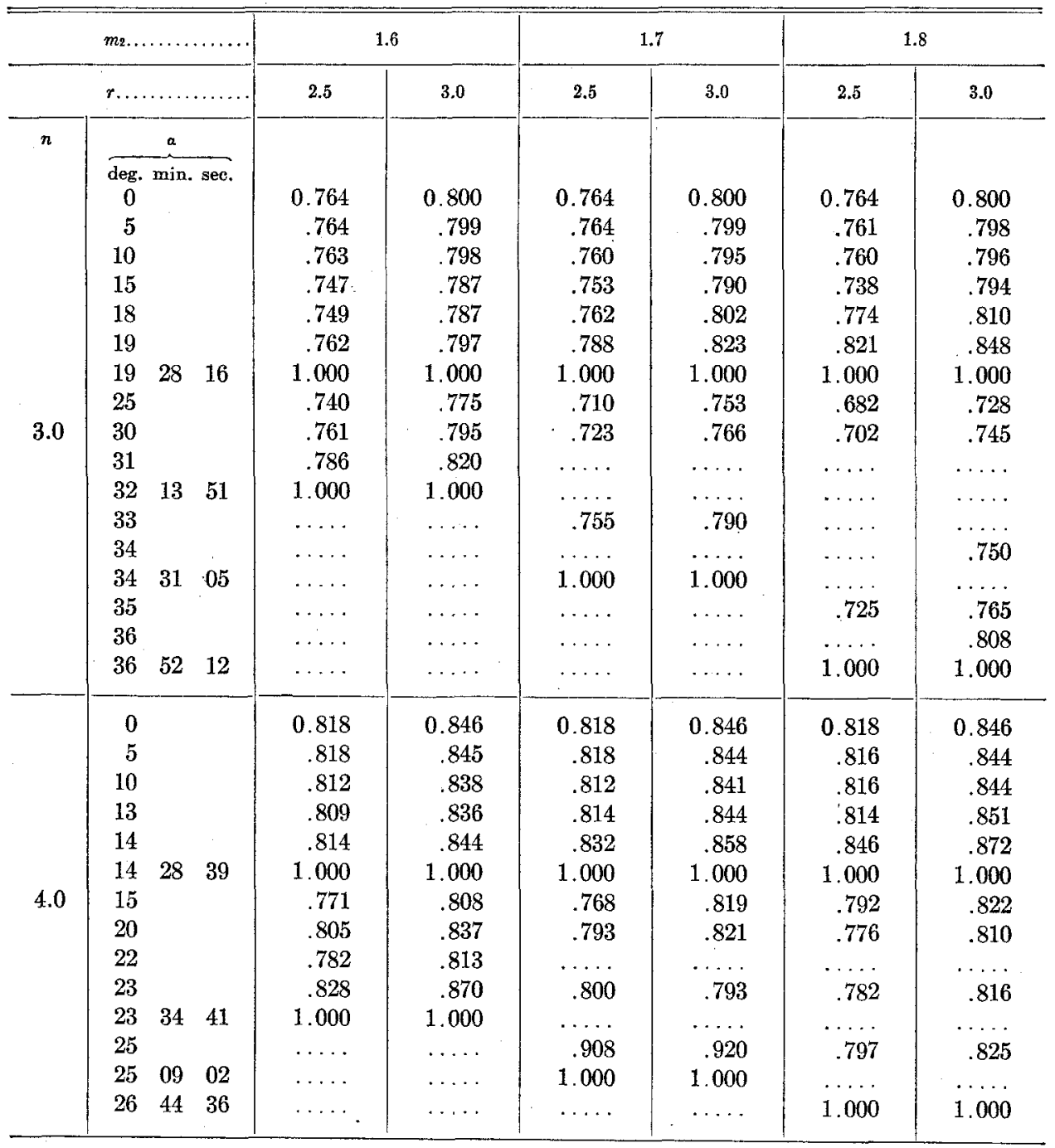


TABLE 7

Incident P Wave in the Water against the Solid: Square Root of the Energy of the Refracted P Wave

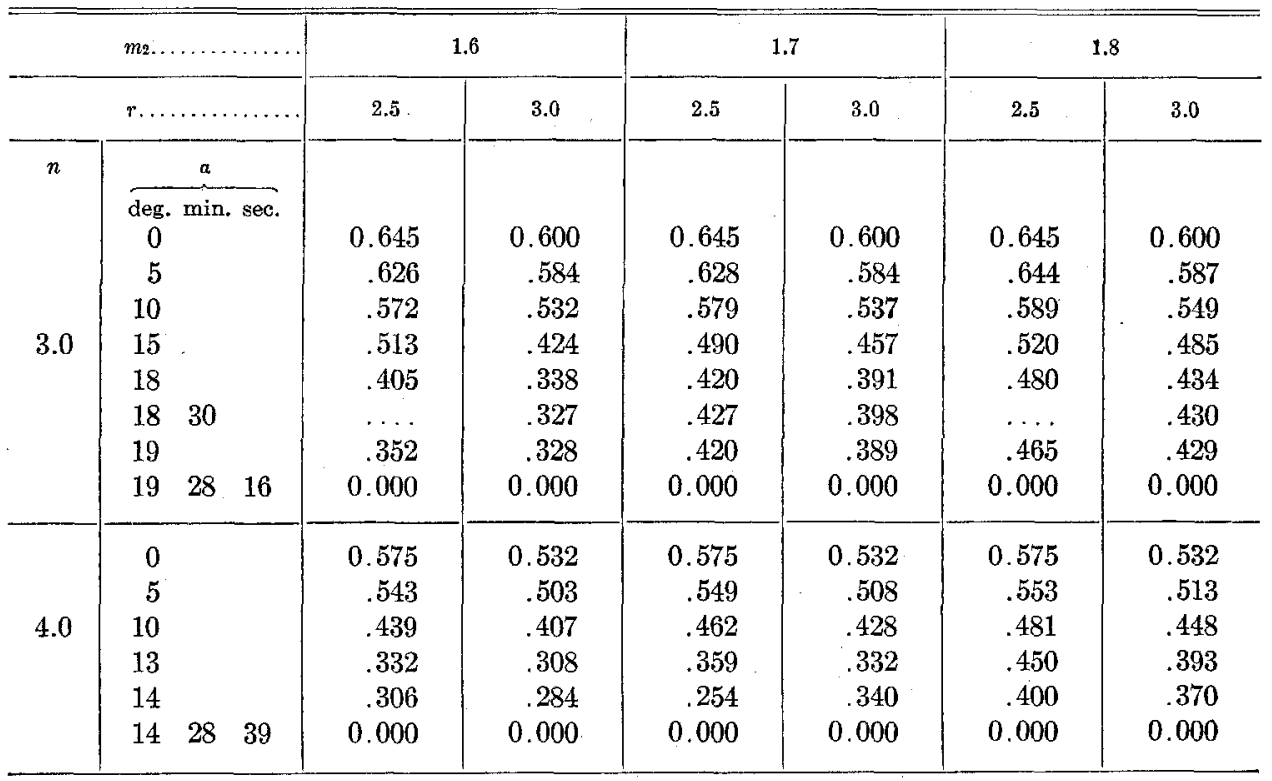


TABLE 8

Incident P Wave in the Water against the Solid: Square Root of the Energy Ratio of the Refracted S Wave

\begin{tabular}{|c|c|c|c|c|c|c|c|c|c|}
\hline \multicolumn{4}{|c|}{$m_{2 .}}$. & \multicolumn{2}{|c|}{1.6} & \multicolumn{2}{|c|}{1.7} & \multicolumn{2}{|c|}{1.8} \\
\hline \multicolumn{4}{|c|}{$r \ldots \ldots$} & 2.5 & 3.0 & 2.5 & 3.0 & 2.5 & 3.0 \\
\hline \multirow[t]{9}{*}{$n$} & \multicolumn{3}{|c|}{$a$} & & & & & & \\
\hline & \multicolumn{3}{|c|}{ deg. min. sec. } & 0.000 & 0.000 & 0.000 & 0.000 & 0.000 & 0.000 \\
\hline & 5 & & & .165 & .151 & .152 & .142 & .142 & .130 \\
\hline & 10 & & & .314 & .298 & .305 & .280 & .274 & .253 \\
\hline & 15 & & & .487 & .455 & .441 & .410 & .398 & .373 \\
\hline & 18 & & & .557 & .520 & .485 & .452 & .427 & .396 \\
\hline & 19 & & & .543 & .503 & .452 & .420 & .351 & .326 \\
\hline & 19 & 28 & 16 & .000 & .000 & .000 & .000 & .000 & .000 \\
\hline & 25 & & & .680 & .637 & .705 & .662 & .732 & .690 \\
\hline \multirow[t]{9}{*}{3.0} & 30 & & & .648 & .605 & .688 & .644 & .695 & .658 \\
\hline & 31 & & & .416 & .387 & $\ldots \ldots$ & $\ldots \ldots$ & $\ldots \ldots$ & $\ldots$. \\
\hline & 32 & 13 & 51 & 0.000 & 0.000 & & & $\ldots \ldots$ & \\
\hline & 33 & & & $\ldots$ & $\ldots$ & .655 & 613 & $\ldots \ldots$ & \\
\hline & 34 & & & $\ldots \ldots$ & $\ldots$ & & & $\ldots \ldots$ & .662 \\
\hline & 34 & 31 & 05 & $\ldots \ldots$ & $\ldots$ & 0.000 & 0.000 & $\ldots \ldots$ & $\ldots \ldots$ \\
\hline & 35 & & & $\ldots \ldots$ & $\ldots$ & $\ldots \ldots$ & $\ldots \ldots$ & .705 & .660 \\
\hline & 36 & & & $\ldots \ldots$ & $\ldots$ & $\ldots \ldots$ & $\ldots \ldots$ & & .598 \\
\hline & 36 & 52 & 12 & $\ldots \ldots$ & $\ldots \ldots$ & $\ldots$ & & 0.000 & 0.000 \\
\hline \multirow{14}{*}{4.0} & 0 & & & 0.000 & 0.000 & 0.000 & 0.000 & 0.000 & 0.000 \\
\hline & 5 & & & .197 & .183 & .181 & .168 & .164 & .153 \\
\hline & 10 & & & .391 & .361 & .345 & .320 & .323 & .299 \\
\hline & 13 & & & .465 & .430 & .438 & .407 & .403 & .352 \\
\hline & 14 & & & .488 & .455 & .417 & .385 & .351 & .325 \\
\hline & 14 & 28 & 39 & .000 & .000 & .000 & .000 & .000 & .000 \\
\hline & 15 & & & .630 & .579 & .550 & .513 & .611 & .566 \\
\hline & 20 & & & .587 & .546 & .612 & .566 & .635 & .590 \\
\hline & 22 & & & .623 & .580 & & $\ldots \ldots$ & & \\
\hline & 23 & & & .519 & .492 & .598 & .555 & .627 & .583 \\
\hline & 23 & 34 & 41 & 0.000 & 0.000 & & & & \\
\hline & 25 & & & $\ldots$. & $\ldots \ldots$ & .424 & .390 & .609 & .565 \\
\hline & 25 & 09 & 02 & $\ldots \ldots$ & $\ldots \ldots$ & 0.000 & 0.000 & $\ldots$ & .. \\
\hline & 26 & 44 & 36 & $\ldots \ldots$ & $\cdots$ & $\ldots$. & $\ldots$ & 0.000 & 0.000 \\
\hline
\end{tabular}


TABLE 9

Incident P Wave in the Water against the Solid: Angles of Incidence at Whrch the Energy Ratio of the Refracted S Wave Has Its Extreme Value

(a) FOR ANGLES OF INCTDENCE GREATER THAN THE CRITTCAL ANGLE OF INCIDENCE

\begin{tabular}{c|c|c|c}
\hline \hline$\ldots \ldots \ldots \ldots \ldots$ & \multicolumn{3}{|c}{3.0} \\
\cline { 2 - 3 }$\ldots \ldots \ldots \ldots$ & 3.0 & 3.5 & 4.0 \\
\hline$m_{2}$ & & & \\
1.6 & 18.3 & 16.0 & 13.7 \\
1.7 & 18.0 & 15.5 & 13.4 \\
1.8 & 17.2 & 15.1 & 13.0 \\
\hline
\end{tabular}

(b) FOR ANGLES OF INCIDENCE LESS THAN THE CRITICAL ANGLE OF INCIDENCE

\begin{tabular}{|c|c|c|c|}
\hline$r \ldots \ldots \ldots$ & \multicolumn{3}{|c|}{3.0} \\
\hline$n \ldots$ & 3.0 & 3.5 & 4.0 \\
\hline$m_{2}$ & & & \\
\hline 1.6 & $20: 3$ & $17: 2$ & $15: 0$ \\
\hline 1.7 & $20: 9$ & $17: 8$ & $15: 4$ \\
\hline 1.8 & 21.8 & $18^{\circ} 6$ & $16^{\circ} .0$ \\
\hline
\end{tabular}

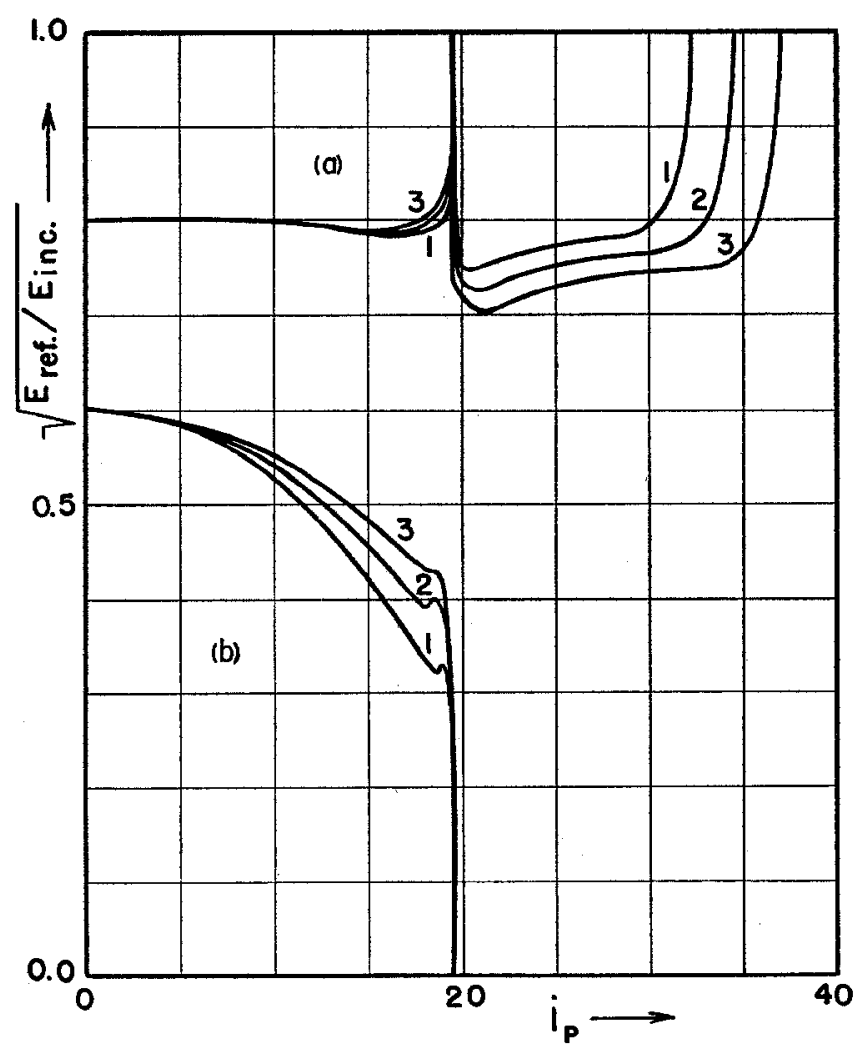

Fig. 5. $P$ wave incident in the water against the solid. (a) Square root of the energy ratio of the reflected $\mathrm{P}$ wave. (b) Square root of the energy ratio of the refracted $P$ wave.

$\begin{array}{cccc}\text { Curve } & V_{2 p} / V_{2 s} & V_{2 p} / V_{1 p} & \rho_{2} / \rho_{1} \\ 1 & 1.6 & 3.0 & 3.0 \\ 2 & 1.7 & 3.0 & 3.0 \\ 3 & 1.8 & 3.0 & 3.0\end{array}$




\section{TABLE 10}

INCIDENT SV WaVe IN the SOLID against the Water: SQUare Root of the Energy Ratto of the Reflected S Wave

(For the purpose of showing the change of sign at zero points, the energy ratio is tabulated with the sign of the amplitude ratio.)

\begin{tabular}{|c|c|c|c|c|c|}
\hline$n \ldots \ldots \ldots$ & \multicolumn{3}{|c|}{0.2} & 0.2 & 0.4 \\
\hline$r \ldots \ldots \ldots \ldots$ & \multicolumn{3}{|c|}{0.3} & 0.4 & 0.3 \\
\hline$m_{1}$ & 1.6 & 1.7 & $1-75$ & 1.7 & 1.7 \\
\hline$\beta$ & & & & & \\
\hline deg. min. sec. & -1.000 & -1.000 & -1.000 & -1.000 & -1.000 \\
\hline 10 & -.859 & -.867 & -.871 & -.870 & -.874 \\
\hline 20 & -.470 & -.503 & -.522 & -.512 & -.530 \\
\hline 30 & +.061 & -.025 & -.077 & -.044 & -.085 \\
\hline 34 & $\ldots \ldots$ & +.086 & $\ldots \ldots$ & +.067 & +.024 \\
\hline $\begin{array}{lll}34 & 51 & 00\end{array}$ & $\ldots$ & $\ldots$ & -1.000 & $\ldots \ldots$ & $\ldots \ldots$ \\
\hline 35 & $\ldots \ldots$ & $\ldots$ & -.922 & $\ldots$ & $\ldots$ \\
\hline $\begin{array}{lll}36 & 01 & 55\end{array}$ & $\ldots$ & -1.000 & $\ldots$ & -1.000 & -1.000 \\
\hline 37 & $\therefore$ & -.872 & $\ldots$ & -.844 & -.749 \\
\hline $\begin{array}{lll}38 & 40 & 56\end{array}$ & -1.000 & $\ldots \ldots$ & $\ldots$ & $\ldots$ & $\ldots$ \\
\hline 40 & -.864 & -.851 & -.845 & -.804 & -.702 \\
\hline 50 & -.878 & -.869 & -.867 & -.829 & -.727 \\
\hline 60 & -.886 & -.875 & -.875 & -.836 & -.736 \\
\hline 70 & -.895 & -.882 & -.880 & -.848 & -.744 \\
\hline 80 & -.927 & -.922 & -.915 & -.904 & -.818 \\
\hline 90 & -1.000 & -1.000 & -1.000 & -1.000 & -1.000 \\
\hline
\end{tabular}


TABLE 11

Incident SV Wave in the Solid against the Water: Angles of Incidence at Which the Energy Ratio of the Reflected S Wave is Zero

\begin{tabular}{|c|c|c|c|c|c|c|c|}
\hline \multicolumn{2}{|c|}{ 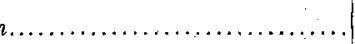 } & \multicolumn{2}{|c|}{0.2} & \multicolumn{2}{|c|}{0.3} & \multicolumn{2}{|c|}{0.4} \\
\hline$r$ & $m_{1}$ & $\beta_{01}$ & $\beta_{02}$ & $\beta_{01}$ & $\beta_{02}$ & $\beta_{01}$ & $\beta_{92}$ \\
\hline 0.3 & $\begin{array}{l}1.60 \\
1.65 \\
1.70 \\
1.725\end{array}$ & 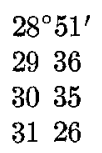 & 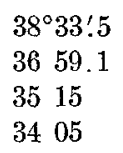 & $\begin{array}{ll}29^{\circ} & 25^{\prime} \\
30 & 12 \\
31 & 19 \\
32 & 46\end{array}$ & $\begin{array}{ll}38^{\circ} & 32: 2 \\
36 & 55.7 \\
35 & 05.8 \\
33 & 23\end{array}$ & $\begin{array}{ll}30^{\circ} & 02^{\prime} \\
30 & 51 \\
32 & 15\end{array}$ & 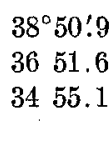 \\
\hline 0.4 & $\begin{array}{l}1.60 \\
1.65 \\
1.70 \\
1.725\end{array}$ & $\begin{array}{ll}29 & 13 \\
30 & 01 \\
31 & 03 \\
32 & 15\end{array}$ & $\begin{array}{ll}38 & 32: 8 \\
36 & 57.1 \\
35 & 11.2 \\
33 & 50\end{array}$ & $\begin{array}{ll}29 & 57 \\
30 & 48 \\
32 & 04\end{array}$ & $\begin{array}{ll}38 & 30: 3 \\
36 & 52.2 \\
34 & 55.5\end{array}$ & $\begin{array}{ll}30 & 50 \\
31 & 44 \\
33 & 22\end{array}$ & $\begin{array}{ll}38 & 29: 1 \\
36 & 46.3 \\
34 & 40.5\end{array}$ \\
\hline
\end{tabular}

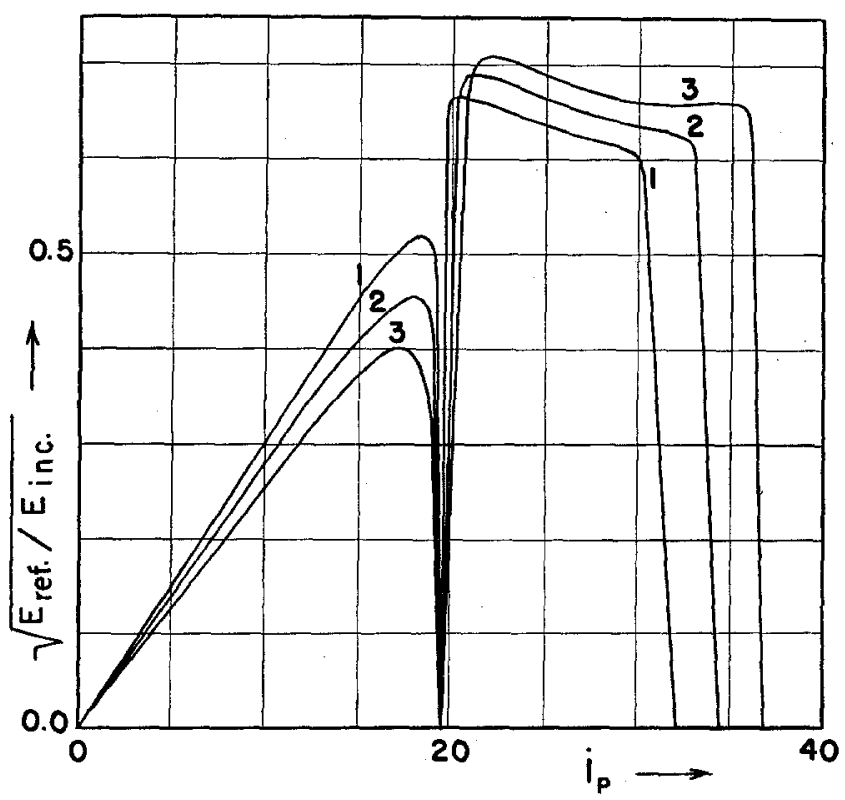

Fig. 6. $\mathrm{P}$ wave incident in the water against the solid. Square root of the energy ratio of the refracted SV wave.

$\begin{array}{cccc}\text { Curve } & V_{2 p} / V_{2 s} & V_{2 p} / V_{1 p} & \rho_{2} / \rho_{1} \\ 1 & 1.6 & 3.0 & 3.0 \\ 2 & 1.7 & 3.0 & 3.0 \\ 3 & 1.8 & 3.0 & 3.0\end{array}$


TABLE 12

Incident SV Wave in the Solid against the Water: Angles of Incidence at Which the Energy Ratio of the Reflected S Wave Has Its Extreme Value

(For the purpose of showing the change of sign at zero points, the energy ratio has been entered in the third column, with the sign of the amplitude ratio.)

\begin{tabular}{|c|c|c|c|c|c|c|c|c|}
\hline$n$. & \multicolumn{2}{|c|}{0.2} & \multicolumn{3}{|c|}{0.3} & \multicolumn{3}{|c|}{0.4} \\
\hline$r$. & & & 0.2 & 0.3 & 0.4 & 0.2 & 0.3 & 0.4 \\
\hline$m_{1}$ & $\beta_{\text {ext }}$ & $d$ & $\beta_{\text {ext }}$ & $\beta_{\text {ext }}$ & $\beta_{\mathrm{ext}}$ & $\beta_{\mathbf{e x t}}$ & $\beta_{\text {ext }}$ & $\beta_{\text {ext }}$ \\
\hline 1.60 & $37^{\circ} 00^{\prime}$ & +.3572 & $36^{\circ} 56^{\prime}$ & $36^{\circ} 58^{\prime}$ & $37^{\circ} 00^{\prime}$ & $36^{\circ} 55^{\prime}$ & $36^{\circ} 57^{\prime}$ & $36^{\circ} 58^{\prime}$ \\
\hline 1.65 & 3510 & +.2142 & 3516 & 3517 & 3518 & & & \\
\hline 1.70 & 3340 & +.0880 & 3343 & 3344 & 3345 & & & \\
\hline 1.7375 & 3230 & +.0000 & & & & & & \\
\hline 1.75 & $32 \quad 10$ & -.0250 & 3219 & 3220 & 3221 & & & \\
\hline 1.80 & 3055 & -.1350 & 3106 & $\begin{array}{ll}31 & 07\end{array}$ & 3108 & & & \\
\hline
\end{tabular}

TABLE 13

Incident SV Wave in the Solid against the Water: Square Root of the Energy Ratio of the Reflected P Wave

\begin{tabular}{|c|c|c|c|c|c|c|c|}
\hline \multicolumn{3}{|l|}{$n .}$. & \multicolumn{3}{|c|}{0.2} & 0.2 & 0.4 \\
\hline \multicolumn{3}{|c|}{$r \ldots \ldots \ldots \ldots$} & \multicolumn{3}{|c|}{0.3} & 0.4 & 0.3 \\
\hline \multicolumn{3}{|l|}{$m_{1}}$. & 1.6 & 1.7 & 1.75 & 1.7 & 1.7 \\
\hline \multicolumn{8}{|c|}{$\beta$} \\
\hline \multicolumn{8}{|c|}{$\overbrace{0}^{\text {deg. min. sec. }}$} \\
\hline 10 & & & .497 & .482 & .475 & .472 & .456 \\
\hline 20 & & & .847 & .831 & .822 & .814 & .783 \\
\hline 25 & & & .928 & .915 & .908 & $\ldots$ & $\ldots$ \\
\hline 28 & & & .939 & .932 & .935 & $\ldots$ & $\ldots$ \\
\hline 30 & & & .933 & .930 & .943 & .912 & .883 \\
\hline 32 & & & .909 & .938 & .929 & $\ldots$ & $\ldots$ \\
\hline 34 & & & $\ldots$ & $\cdots$ & $\ldots$ & .920 & .898 \\
\hline 34 & 51 & 00 & $\ldots$ & $\ldots$ & 0.000 & $\ldots$ & $\ldots$ \\
\hline 35 & & & .846 & .948 & $\ldots$ & $\ldots$ & $\ldots$ \\
\hline 36 & & & .854 & $\ldots$ & $\ldots$ & $\ldots$ & $\ldots$ \\
\hline & 01 & 55 & $\cdots$ & 0.000 & $\ldots$ & 0.000 & 0.000 \\
\hline 37 & & & .857 & $\therefore$ & $\ldots$ & $\ldots$ & $\ldots$ \\
\hline 38 & & & .887 & $\ldots$ & $\ldots$ & $\ldots$ & $\ldots$ \\
\hline 38 & 40 & 56 & 0.000 & $\ldots$ & $\ldots$ & $\ldots$ & . \\
\hline
\end{tabular}


TABLE 14

Incident SV Wave in the Solid against the Water: Square Root of the ENergy Ratio of the Refracted P Wavf

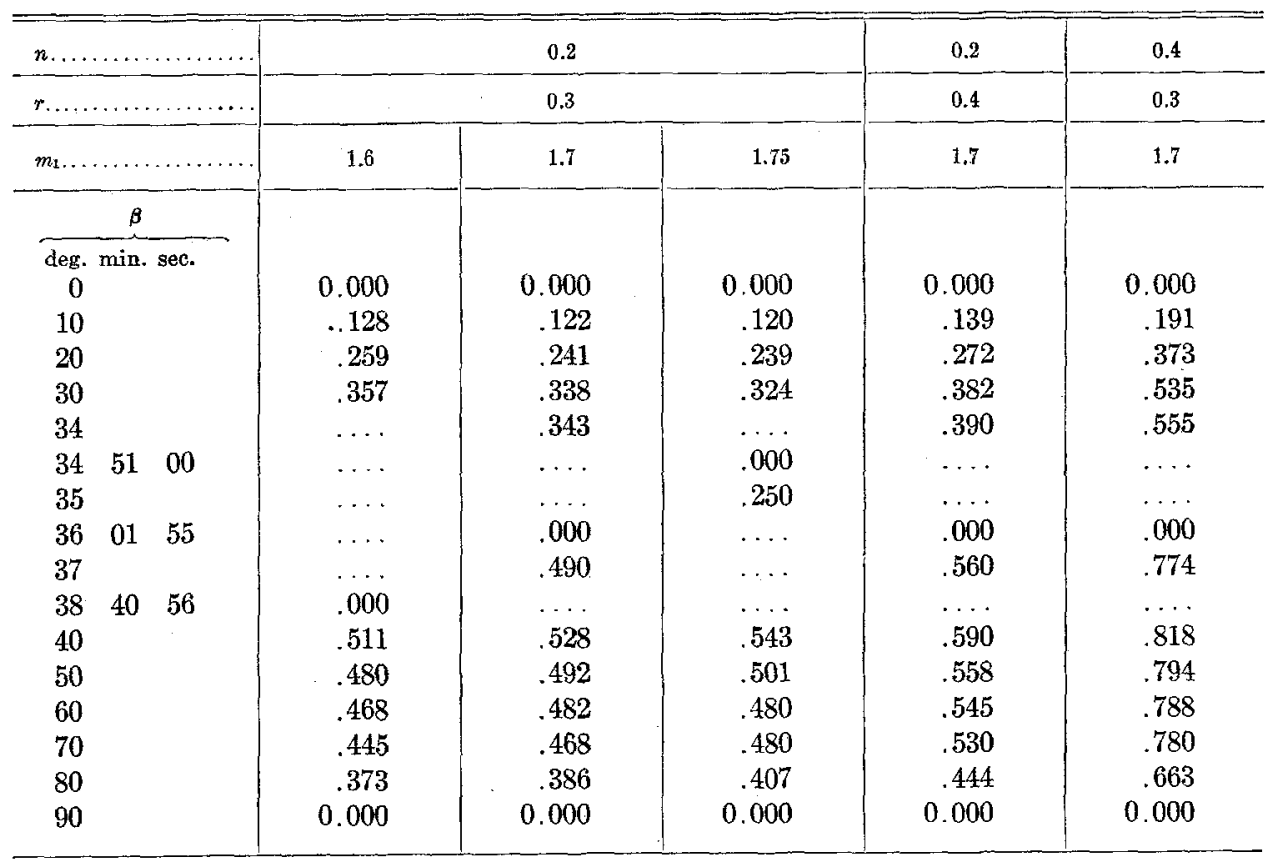

TABLE 15

Inctoent SV Wave In the Solid against the Water: Angles of INcidence at Which the Energy Ratio of the Refracted P Wave Has Its Extreme VALUe

\begin{tabular}{|c|c|c|c|c|}
\hline \multicolumn{2}{|c|}{$r \ldots \ldots \ldots \ldots \ldots \ldots \ldots \ldots$} & 0.2 & 0.3 & 0.4 \\
\hline$n$ & $m_{1}$ & $\beta_{\text {ext }}$ & $\beta_{\mathrm{ext}}$ & $\beta_{e x t}$ \\
\hline \multirow{3}{*}{0.2} & 1.60 & $36^{\circ} 12^{\prime}$ & $36^{\circ} 19^{\prime}$ & $36^{\circ} 26^{\prime}$ \\
\hline & 1.70 & $\cdots$ & 3245 & $\cdots \cdots$ \\
\hline & 1.75 & & 3115 & $\cdots \cdots$ \\
\hline 0.3 & 1.60 & 3610 & 3616 & 3623 \\
\hline
\end{tabular}




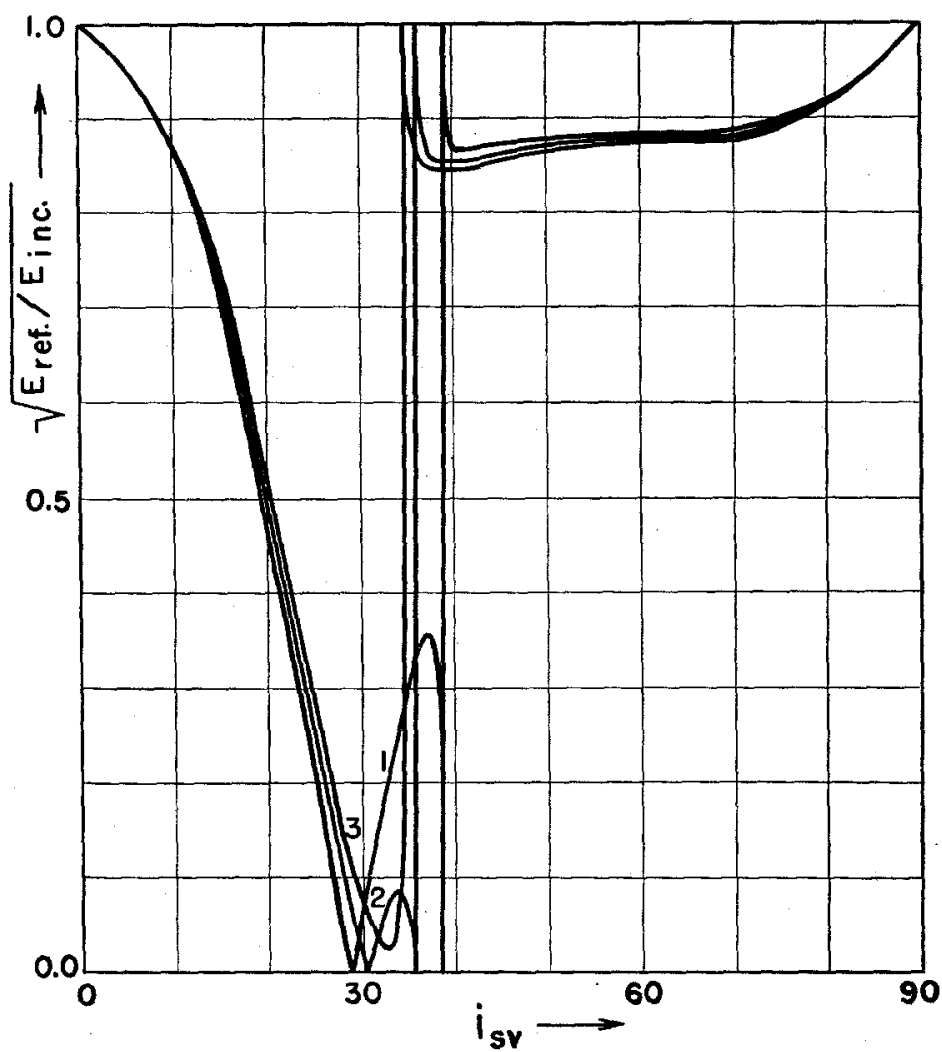

Fig. 7. SV wave incident in the solid against the water. Square root of the energy ratio of the reflected $\mathrm{SV}$ wave.

$\begin{array}{cccc}\text { Curve } & V_{1 p} / V_{1 s} & V_{2 p} / V_{1 p} & \rho_{2} / \rho_{1} \\ 1 & 1.6 & 0.2 & 0.3 \\ 2 & 1.7 & 0.2 & 0.3 \\ 3 & 1.75 & 0.2 & 0.3\end{array}$

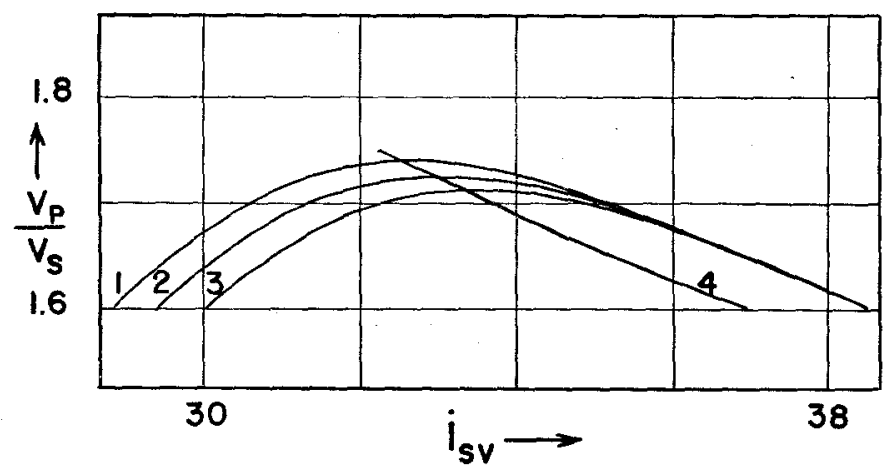

Fig. 8. SV wave incident in the solid against the water.

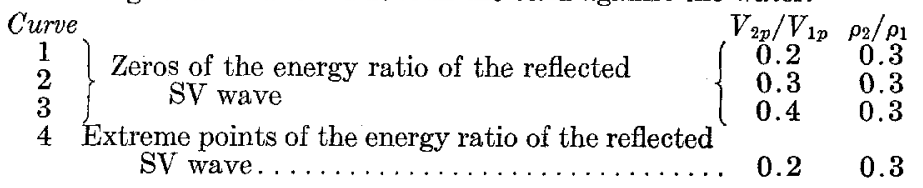




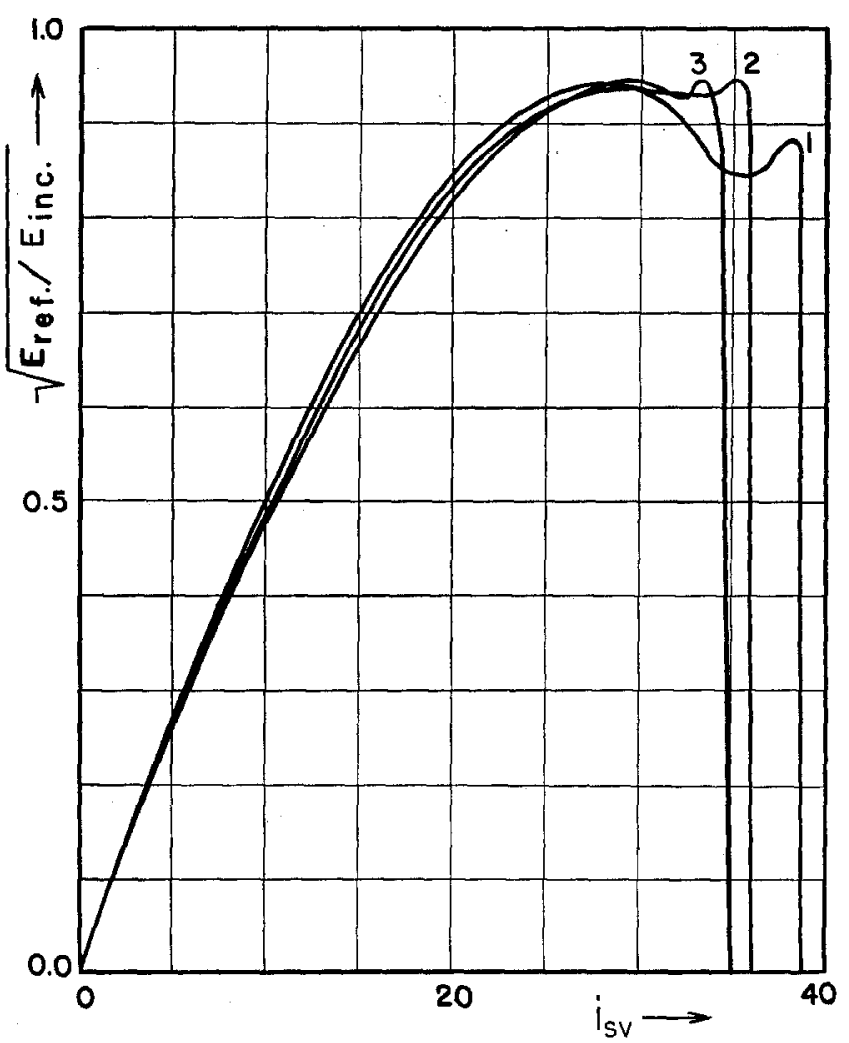

Fig. 9. SV wave incident in the solid against the water. Square root of the energy ratio of the reflected $P$ wave.

$\begin{array}{cccc}\text { Curve } & V_{1 p} / V_{1 s} & V_{2 p} / V_{1 p} & \rho_{2} / \rho_{1} \\ 1 & 1.6 & 0.2 & 0.3 \\ 2 & 1.7 & 0.2 & 0.3 \\ 3 & 1.75 & 0.2 & 0.3\end{array}$




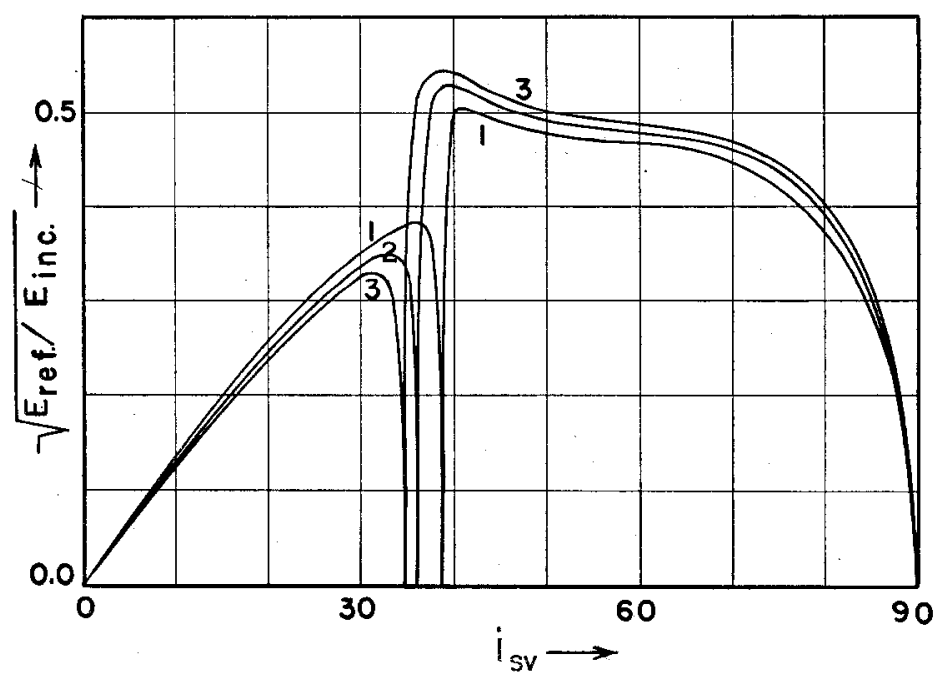

Fig. 10. SV wave incident in the solid against the water. Square root of the energy ratio of the refracted $\mathrm{P}$ wave.

$\begin{array}{cccl}\text { Curve } & V_{1 p} / V_{1 s} & V_{2 p} / V_{1 p} & \rho_{2} / \rho_{1} \\ 1 & 1.6 & 0.2 & 0.3 \\ 2 & 1.7 & 0.2 & 0.3 \\ 3 & 1.75 & 0.2 & 0.3\end{array}$




\section{Summary and Conclusions}

General behavior, zeros, and extreme points of different type of waves incident at both sides of the ocean floor, for some values of parameters $m, n$, and $r$ which are considered to include actual values, are computed; computed values are tabulated and plotted.

The following general conclusions are drawn from the results:

1. Poisson's ratio $\sigma$ of the solid medium is a dominating factor in the general behavior, zeros, and extreme points of the reflected and refracted waves that travel in the solid and are produced by any possible type of wave incident at either side of the solid-water boundary.

2. $n$ dominates the behavior of refracted waves and also plays an important role in the behavior of all waves around the critical incidence for $\eta=90^{\circ}$.

3. General behavior of any wave that is produced by incidence of any type of wave at either side of the boundary is affected very little by changing $r$, the effect usually being negligibly small.

4. In all cases the values of $a_{\text {ext }}$ or $\beta_{\text {ext }}$ change very slightly by changing $r$. The same statement is true for $n$ except where the occurrence of extreme value is due to a total reflection at $\eta=90^{\circ}$.

5. In all cases considered in this paper, peculiar behaviors are observed just before and right after the critical angles of incidence.

6 . At a critical angle of incidence the whole energy goes into the reflected wave of the same kind as the incident wave.

7. In all cases considered, most of the energy goes into reflected $\mathrm{P}$ or $\mathrm{S}$ wave, depending on the angle of incidence. This can be explained by large contrast between densities and velocities in two media. In the case of a $\mathrm{P}$ wave incident in the water against the solid, after $\alpha_{c \eta}$ the energy is split between reflected $\mathrm{P}$ wave and refracted $\mathrm{S}$ wave but still a larger part goes into the reflected $\mathrm{P}$ wave.

\section{ACKNOWLEDGMENTS}

The writer owes a debt of gratitude to Dr. B. Gutenberg, who supervised the work and gave generous constructive criticism at its different stages. He also wishes to express his thanks to Dr. C. F. Richter, who made very váluable suggestions.

California Institute of Teghnology

Pasadena, California

(Division of the Geological Sciences, contribution no. 548) 